\title{
Conservation status of the dhole Cuon alpinus in north-east India, with a focus on Dampa Tiger Reserve, Mizoram
}

\author{
Priya Singh, Arjun Srivathsa and David W. Macdonald
}

\begin{abstract}
Despite the efforts invested in their conservation, the status of many threatened carnivores in key conservation landscapes remains unknown. The dhole Cuon alpinus is an Endangered social carnivore whose geographical range has contracted by c. $80 \%$ since the early 20 th century. North-east India is a critical link between South Asian and South-east Asian dhole populations. In this study we compiled presence records of dholes across north-east India, from multiple sources. We also conducted camera-trap surveys in one part of this region, Dampa Tiger Reserve in the state of Mizoram. We examined the influence of ecological and management factors on fine-scale site-use by dholes in Dampa Tiger Reserve, showing a positive association of dhole site-use with sambar Rusa unicolor encounters, distance to the forest boundary and presence of forest department personnel, underscoring the importance of prey and protection. Our findings also highlight the need for targeted, multi-scale assessments of dhole ecology across other sites in north-east India.
\end{abstract}

Keywords Camera traps, Cuon alpinus, distribution, dhole, Endangered, management, north-east India

Supplementary material for this article is available at https://doi.org/10.1017/So030605319000255

$\mathrm{T}$ he dhole Cuon alpinus is an Endangered social carnivore found in forested landscapes of South and South-east Asia. Historically widespread across Asia, the species' range has contracted by c. $80 \%$ (Wolf \& Ripple, 2017). The current distribution extends across most of South and South-east Asia and parts of China but is largely restricted to protected areas (Kamler et al., 2015). The protected forest landscapes south of the River Ganges in India

PRIYA SINGH Researchers for Wildlife Conservation, National Centre for Biological Sciences, GKVK Campus, Bengaluru, India

Arjun SRIVATHSA (Corresponding author, (D) orcid.org/0000-0003-2935-3857) Department of Wildlife Ecology and Conservation, University of Florida, Gainesville, USA. E-mail asrivathsa@ufl.edu

David W. Macdonald Department of Zoology, Wildlife Conservation Research Unit, Recanati-Kaplan Centre, University of Oxford, Tubney, Abingdon, UK

*Also at: School of Natural Resources and Environment, University of Florida, Gainesville, USA, and Wildlife Conservation Society-India, Bengaluru, India

Received 6 September 2018. Revision requested 6 November 2018.

Accepted 26 February 2019. First published online 23 October 2019. are a stronghold for the species (Acharya, 2007; Srivathsa et al., 2014; Punjabi et al., 2017), with the largest dhole population (Kamler et al., 2015). However, the species has undergone local extirpation across parts of its former range as a result of declines of prey species, loss of habitat and, potentially, disease (Karanth et al., 2010; Srivathsa et al., 2014). Information on dholes in north-east India in particular is limited (Gopi et al., 2010; Bashir et al., 2014; Lyngdoh et al., 2014), despite the fact that this landscape shares continuous forest with Myanmar and South-east Asia, forming an important part of the species' global range.

Current knowledge of dholes in north-east India is restricted to landscapes north of the River Brahmaputra (Ginsberg \& Macdonald, 1990). This is primarily because of the paucity of baseline ecological data from the region, given its undulating terrain, difficulty of access, wet climatic conditions, and socio-political insurgencies. Here we provide a compilation of dhole presence records from across north-east India using data extracted from multiple sources. Using data from camera-trap surveys we examine factors influencing fine-scale site-use by dholes in Dampa Tiger Reserve, Mizoram State. We discuss the implications of our results for dhole conservation in north-east India, where the focus of wildlife managers is directed mainly towards population recoveries of and local recolonization by the tiger Panthera tigris. We provide recommendations for management interventions that could facilitate conservation of dholes in this hitherto neglected landscape.

Dampa Tiger Reserve lies in the Indo-Myanmar Biodiversity Hotspot (Mittermeier et al., 2004; Fig. 1). The reserve is contiguous with the Chittagong Hill Tract region of Bangladesh to the west. The core area of the Reserve covers $500 \mathrm{~km}^{2}$, and the multi-use buffer covers an area of $488 \mathrm{~km}^{2}$. The Lushai Hills traverse the reserve, with altitudes of $250-1,100 \mathrm{~m}$. Mean annual rainfall is $2,000-2,500 \mathrm{~mm}$ (Islam \& Rahmani, 2004). The Reserve supports a high diversity of carnivores, including, in addition to the dhole, four species of felids and two species of ursids (Singh \& Macdonald, 2017). In this study we also recorded the elephant Elephas maximus, gaur Bos gaurus, sambar Rusa unicolor, red serow Capricornis rubidus, muntjac Muntiacus muntjak and wild pig Sus scrofa.

We compiled dhole presence records for nine northeastern states (Arunachal Pradesh, Assam, Manipur, Meghalaya, Mizoram, Nagaland, Sikkim, Tripura and West Bengal). We searched for records from 1990 onwards 


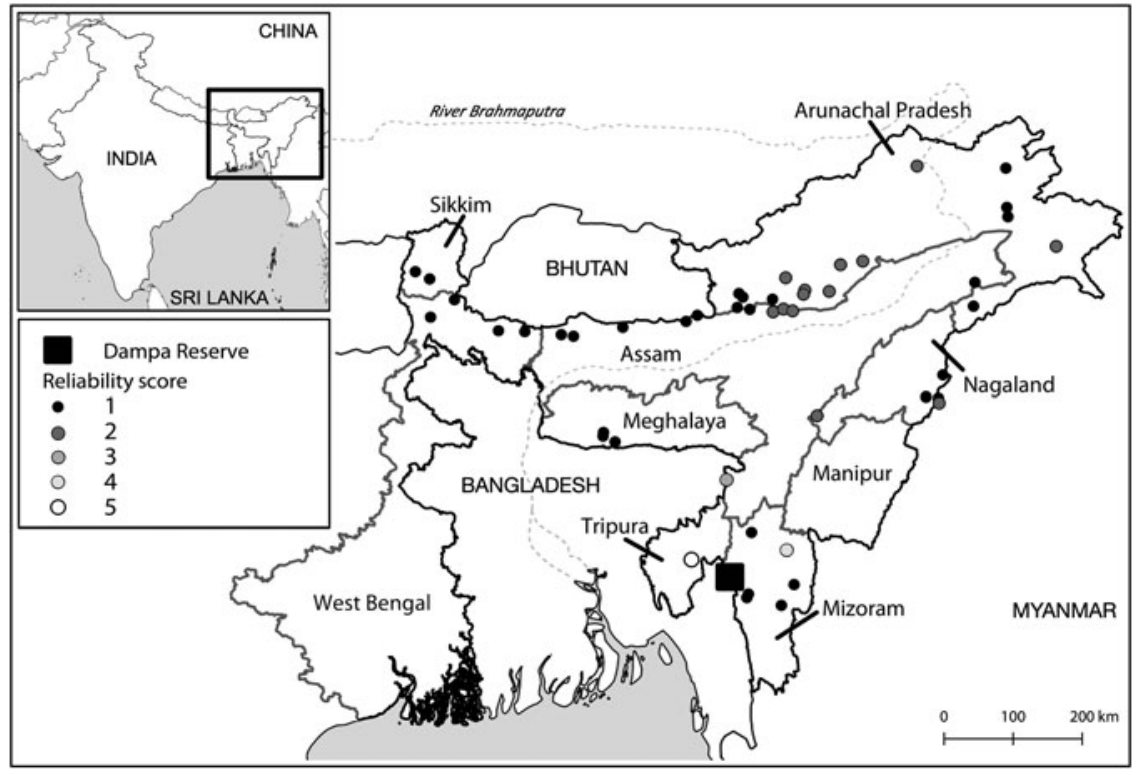

FIG. 1 North-east India, with Dampa Tiger Reserve in Mizoram and locations where the dhole Cuon alpinus has been recorded, with corresponding reliability scores (see text for details). in newspaper reports, scientific articles, grey literature (including species checklists), and reports by forest department personnel, local informants and naturalists working in the region. For each record we noted the type of evidence (direct/indirect), date of sighting, administrative status of location (protected/non-protected), and source person or reference. We assigned reliability scores for each record (1-5; with 1 being most reliable, and 5 least reliable; Supplementary Table 1).

From December 2014 to March 2015, we deployed 79 pairs of Cuddeback Ambush IR camera traps (Model 1187; Cuddeback, De Pere, USA) across $80 \mathrm{~km}^{2}$ in the north-east of Dampa Tiger Reserve's core area. At each station we placed two cameras facing each other, c. $30 \mathrm{~cm}$ above the ground, on either side of forest trails or on riverbeds (Singh \& Macdonald, 2017). Mean inter-trap distance was $1.02 \pm \mathrm{SD} 0.33 \mathrm{~km}$, with traps remaining active for an average of 64 days (range 3-91; Singh \& Macdonald, 2017). Although the stations were intended to photograph wild felids, they also photographed other carnivores. Dholes generally use forest trails and riverbeds for movement, marking territories and hunting, and our sampling design therefore incorporated areas used by the species.

We examined site-use patterns through an occupancy approach that accounted for imperfect detection (MacKenzie et al., 2002). We treated each station as a site, and each trap-day as an independent temporal replicate. During exploratory analyses we calculated Moran's I to check for spatial dependence of detections. Spatial dependence dropped beyond $2.3 \mathrm{~km}$, with $<10 \%$ of distance-pairs falling within the first distance class (Supplementary Fig. 1). We considered this to be negligible with respect to the total number of trap stations and detections, and therefore treated each station as an independent site. The detection matrix therefore contained non-detections and detections (coded as 0 and 1 , respectively) for 74 sites (data from five sites could not be retrieved), with a varying number of temporal replicates (3-91 days).

We used photo-capture frequencies of key prey species ( sambar $\mathrm{n}=236$, muntjac $\mathrm{n}=145$, wild pig $\mathrm{n}=92$; predicted positive influence), distance to reserve boundary (predicted positive influence), photo-capture frequencies of forest department personnel (predicted positive influence) and photo-capture frequencies of other humans (predicted negative influence) as factors likely to influence site-use by dholes. We used trap effort (number of days a trap station was active) at each site as a covariate for detection probability, predicting that higher effort would translate to higher detectability. We tested singular and additive effects of the covariates, in which each represented an ecologically plausible hypothesis. Covariates were checked for crosscorrelations and $z$-transformed prior to analyses. Models were ranked using Akaike information criterion corrected for small sample sizes (AICc; Burnham \& Anderson, 2002). Parameter estimation and model comparisons were calculated with PRESENCE 11.9 (Hines, 2006).

We obtained presence records from 80 locations for 1990-2018, of which we considered 41 records from 20102018 with reliability scores of 1-3 (Supplementary Table 2). In the case of multiple records for the same site, we considered the most recent record with the highest reliability score. Most records were from Arunachal Pradesh $(n=14)$ and Assam $(n=8)$, with five records from Mizoram and Nagaland, four from West Bengal, three from Meghalaya and two from Sikkim. There were no recent records of dholes from Manipur and Tripura. A total of 5,033 camera trap-days in Dampa Tiger Reserve generated 500 photoencounters of dholes, comprising 92 detections (one per 
TABLE 1 The 11 top-ranked models (based on AICc scores) and the intercept-only model [psi(.), p(.)] for the probability of site-use by dholes in Dampa Tiger Reserve, Mizoram during December 2014-March 2015.

\begin{tabular}{|c|c|c|c|c|c|c|}
\hline Model $^{1}$ & AICc & $\Delta \mathrm{AICc}$ & AICc weight & Model likelihood & Parameters & Deviance \\
\hline$\overline{p s i(s b r+f d p+b d y), p(e f f)}$ & 862.47 & 0 & 0.4041 & 1 & 6 & 850.47 \\
\hline$p s i(s b r+f d p), p(e f f)$ & 863.24 & 0.77 & 0.2750 & 0.6805 & 5 & 853.24 \\
\hline$p s i(s b r+f d p+b d y+h u m), p(e f f)$ & 863.98 & 1.51 & 0.1899 & 0.4700 & 7 & 849.98 \\
\hline$p s i(s b r), p(e f f)$ & 867.29 & 4.82 & 0.0363 & 0.0898 & 4 & 859.29 \\
\hline$p s i(s b r+b d y), p(e f f)$ & 867.74 & 5.27 & 0.0290 & 0.0717 & 5 & 857.74 \\
\hline$p s i(s b r+p i g), p(e f f)$ & 868.28 & 5.81 & 0.0221 & 0.0547 & 5 & 858.28 \\
\hline$p s i(s b r+h u m), p(e f f)$ & 868.32 & 5.85 & 0.0217 & 0.0537 & 5 & 858.32 \\
\hline$p s i(s b r+p i g+m j k), p(e f f)$ & 870.24 & 7.77 & 0.0083 & 0.0205 & 6 & 858.24 \\
\hline$p s i(f d p+b d y), p(e f f)$ & 870.74 & 8.27 & 0.0065 & 0.0160 & 5 & 860.74 \\
\hline$p s i(b d y), p(e f f)$ & 873.22 & 10.75 & 0.0019 & 0.0046 & 4 & 865.22 \\
\hline$p s i(f d p), p(e f f)$ & 873.55 & 11.08 & 0.0016 & 0.0039 & 4 & 865.55 \\
\hline$p s i(),. p()$. & 874.19 & 11.72 & 0.0012 & 0.0029 & 2 & 870.19 \\
\hline
\end{tabular}

${ }^{1}$ sbr, sambar encounter frequency; fdp, encounters of forest department personnel; bdy, distance to reserve boundary; eff, trap effort; hum, human activity; pig, wild pig encounter frequency; mjk, muntjac encounter frequency.

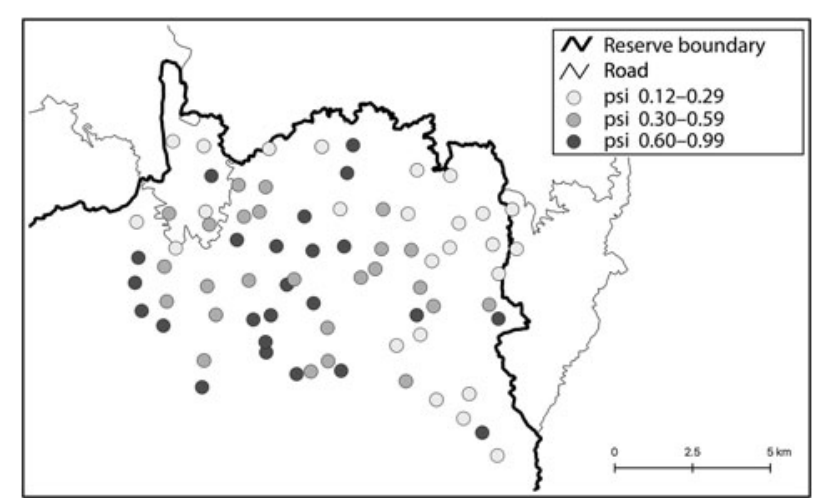

FIg. 2 Estimates of probabilities of site-use (psi) by dholes in Dampa Tiger Reserve (Fig. 1) during December 2014-March 2015, based on camera-trap surveys and occupancy modelling.

24 hour duration) across 33 sites. Using the top-ranked occupancy model (Table 1), we estimated mean site-use probability to be psi $=0.50 \pm$ SE 0.03 (Fig. 2) and trap-level detectability to be $\mathrm{P}=0.87 \pm$ SE 0.02 . The top three models received similar support based on AICc scores; we interpret the covariate effects on probability of site-use from these models. Sambar encounters, forest department personnel encounters and distance to reserve boundary had positive effects on probability of site-use by dholes (Table 2, Fig. 3). The slope coefficient associated with effort as a covariate for detectability was positive (mean $=0.23 \pm \mathrm{SE} 0.2$ ).
There are records of dholes across several areas of north-east India, including in unprotected areas. Previous global assessments indicated that the species faced near or complete local extirpation to the south of the River Brahmaputra (Ginsberg \& Macdonald, 1990), contrary to our findings from Dampa Tiger Reserve. Corroborating current knowledge from other landscapes, we found a positive relationship between dhole site-use and sambar presence (Acharya, 2007; Andheria et al., 2007; Punjabi et al., 2017). Across their extant distribution, the range of dholes overlaps with that of tigers and leopards Panthera pardus. Wildlife managers in this region and elsewhere subscribe to unsubstantiated notions that dhole presence impedes colonization by tigers (P. Singh, pers. comm.), and consequently treat dholes as a problem species. On the contrary, tigers, leopards and dholes can exist provided protected areas support adequate densities of medium- to large-sized prey species (Karanth et al., 2017).

Dampa Tiger Reserve is an important refuge for dholes in north-east India. It supports large tracts of inviolate protected spaces, and habitat connectivity with forested landscapes of the Chittagong Hill Tract region to the west, Mamit Forest Division to the north and Thorangtlang Wildlife Sanctuary to the south. Our camera-trap data indicate the presence of a guild of large herbivores in the Reserve, with at least five prey species of medium and large ungulate herbivores, facilitating the long-term

TABLE 2 Slope coefficient estimates \pm SE for ecological and management covariates for the top three models (i.e. those with AICc scores $<2$; Table 1) influencing site-use by dholes in Dampa Tiger Reserve, Mizoram during December 2014-March 2015.

\begin{tabular}{llll}
\hline Model $^{1}$ & sbr & fdp & bdy \\
\hline$p s i(s b r+f d p+b d y), p(e f f)$ & $1.35 \pm 0.59$ & $0.86 \pm 0.45$ & $0.54 \pm 0.34$ \\
$p s i(s b r+f d p), p(e f f)$ & $1.36 \pm 0.55$ & $0.76 \pm 0.42$ & \\
$p s i(s b r+f d p+b d y+h u m), p(e f f)$ & $1.29 \pm 0.58$ & $1.12 \pm 0.72$ & $0.51 \pm 0.34$ \\
\hline
\end{tabular}

${ }^{1}$ sbr, sambar encounter frequency; fdp, encounters of forest department personnel; bdy, distance to reserve boundary; hum, human activity. 


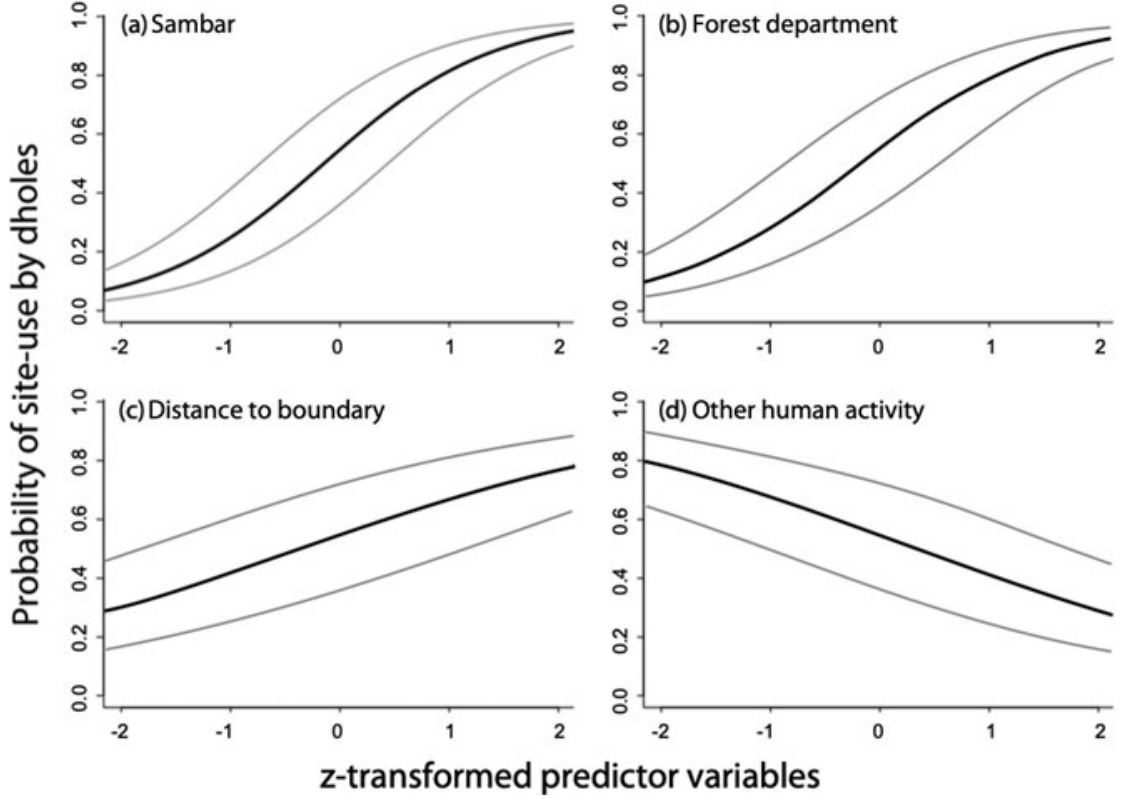

FIG. 3 The effect of (a) sambar Rusa unicolor encounter frequency, (b) forest department staff encounter frequency, (c) distance to reserve boundary, and (d) other human encounter frequency on the probability of site-use by dholes in Dampa Tiger Reserve during December 2014-March 2015. Grey lines indicate 95\% confidence intervals. persistence of dholes there. Our findings re-emphasize the importance of protected areas, which can serve as source sites for sustaining dhole populations across the region.

In areas with low prey densities, carnivores may have significant dependence on livestock (Khorozyan et al., 2015), and are consequently stigmatized. There is a strong negative relationship between dholes and livestock owners in Arunachal Pradesh (Mishra et al., 2004; Lyngdoh et al., 2014) and other locations in the region. Given that dholes also occur outside protected areas in this region, they are potentially vulnerable to retributory killing. Negative interactions between people and dholes necessitate interventions to reduce poaching and facilitate recovery of prey, especially for species such as sambar that are impacted by low recovery rates following prolonged poaching (Steinmetz et al., 2009). Our findings need to be augmented with a systematic survey across the locations we identified, specifically in the states of Mizoram and Nagaland, to facilitate a pan-north-east India strategy for dhole conservation.

Acknowledgements We thank $\mathrm{Pu}$ Liandawla for granting us permission to work in Dampa Tiger Reserve, Pu Laltlanhlua and $\mathrm{Pu}$ Lalrinmawia for administrative and logistic support, Nandita Hazarika, Ecosystem-India, and Alexandra Zimmerman, WildCRU and Chester Zoo, for coordinating and administering this study, Assistant Conservator of Forest Pu Vanlalrema, Range Officer Pu Vanlalbera, D. Barman, K. Lalthanpuia and others for field support, the Robertson Foundation for a grant to DWM for funding the cameratrap study, and the Editor and two anonymous reviewers for feedback. AS was supported by the University of Florida, Wildlife Conservation Society's Christensen Conservation Leaders Scholarship, and Wildlife Conservation Network's Sidney Byers Fellowship.

Author contributions Conception: PS, AS, DWM; data collection: PS; data analysis: PS, AS; writing: all authors, lead by PS.

Conflicts of interest None.
Ethical standards This research abided by the Oryx guidelines on ethical standards. Data on presence records were obtained from published literature, media reports, and a network of researchers and naturalists who agreed to share information. All necessary research permits for camera-trap surveys were obtained from the State Forest Department of Mizoram.

\section{References}

Acharya, B.B. (2007) The ecology of the dhole or Asiatic wild dog (Cuon alpinus) in Pench Tiger Reserve, Madhya Pradesh. PhD thesis. Saurashtra University, Rajkot, India.

Andheria, A.P., Karanth, K.U. \& Kumar, N.S. (2007) Diet and prey profiles of three sympatric large carnivores in Bandipur Tiger Reserve, India. Journal of Zoology, 273, 169-175.

Bashir, T., Bhattacharya, T., Poudyal, K., Roy, M. \& Sathyakumar, S. (2014) Precarious status of the Endangered dhole Cuon alpinus in the high elevation Eastern Himalayan habitats of Khangchendzonga Biosphere Reserve, Sikkim, India. Oryx, 48, 125-132. Burnham, K.P. \& Anderson, D.R. (2002) Model Selection and Multimodel Inference: a Practical Information Theoretic Approach. 2nd edition. Springer-Verlag, New York, USA.

Ginsberg, J.R. \& Macdonald, D.W. (1990) Foxes, Wolves, Jackals and Dogs: an Action Plan for the Conservation of Canids. IUCN/Species Survival Commission Canid Specialist Group, Gland, Switzerland.

Gopi, G.V., Lyngdoh, S. \& Selvan, K.M. (2010) Conserving the Endangered Asiatic Wild Dog Cuon alpinus in Western Arunachal Pradesh: Fostering Better Coexistence for Conservation. Final Technical Report submitted to Rufford Small Grants Programme, London UK.

Hines, J.E. (2006) PRESENCE-Software to Estimate Patch Occupancy and Related Parameters. USGS-PWRC. Http://www.mbr-pwrc.usgs. gov/software/presence.html [accessed 18 August 2018].

Islam, M.Z. \& Rahmani, A.R. (2004) Important Bird Areas in India: Priority Sites for Conservation. Bombay Natural History Society, Mumbai, India, and BirdLife International, Cambridge, UK.

Kamler, J.F., Songsasen, N., Jenks, K., Srivathsa, A., Sheng, L. \& KunkeL, K. (2015) Cuon alpinus. In The IUCN Red List of Threatened Species 2015. Http://dx.doi.org/10.2305/IUCN.UK.20154.RLTS.T5953A72477893.en [accessed 18 August 2018]. 
Karanth, K.K., Nichols, J.D., Karanth, K.U., Hines, J.E. \& Christensen, N.L. (2010) The shrinking ark: patterns of large mammal extinctions in India. Proceedings of the Royal Society Biological Sciences, 277, 1971-1979.

Karanth, K.U., Srivathisa, A., Vasudev, D., Puri, M., Parameshwaran, R. \& Kumar, N.S. (2017) Spatio-temporal interactions facilitate large carnivore sympatry across a resource gradient. Proceedings of the Royal Society B: Biological Sciences, 284, 20161860.

Khorozyan, I., Ghoddousi, A., Soofi, M. \& Waltert, M. (2015) Big cats kill more livestock when prey reaches a minimum threshold. Biological Conservation, 192, 268-275.

Lyngdoh, S., Gopi, G.V., Selvan, K.M. \& Habib, B. (2014) Effect of interactions among ethnic communities, livestock and wild dogs (Cuon alpinus) in Arunachal Pradesh, India. European Journal of Wildlife Research, 60, 771-780.

MacKenzie, D.I., Nichols, J.D., Lachman, G.B., Droege, S., Royle, J.A. \& LANGTimm, C.A. (2002) Estimating site occupancy rates when detection probabilities are less than one. Ecology, $83,2248-2255$.

Mishra, C., Datta, A. \& Madhusudan, M.D. (2004) The High Altitude Wildlife of Western Arunachal Pradesh: a Survey Report. Unpublished Report. Nature Conservation Foundation,
International Snow Leopard Trust, and Wildlife Conservation Society (India Program), Mysore, India.

Mittermeier, R.A., Robles-Gil, R., Hoffman, M., Pilgrim, J., Brooks, T., Mittermeier, C.G. et al. (2004) Hotspots Revisited: Earth's Biologically Richest and Most Endangered Terrestrial Ecoregions. CEMEX, Mexico City, Mexico.

Punjabi, G.A., Edgaonkar, A., Srivathisa, A., Ashtaputre, S. \& RAO, M.K. (2017) Distribution of the dhole in its northern range limits in the Western Ghats, India. Canid Biology and Conservation, 20, 7-13.

Singh, P. \& Macdonald, D.W. (2017) Population and activity patterns of clouded leopards and marbled cats in Dampa Tiger Reserve, India. Journal of Mammalogy, 98, 1453-1462.

Srivathsa, A., Karanth, K.K., Jathanna, D., Kumar, N.S. \& KARANTH, K.U. (2014) On a dhole trail: examining ecological and anthropogenic correlates of dhole habitat occupancy in the Western Ghats of India. PLOS ONE, 6, e98803.

Steinmetz, R., Chutipong, W., Seuaturien, N., Chirngsaard, E. \& Khaengkhetkarn, M. (2009) Population recovery patterns of Southeast Asian ungulates after poaching. Biological Conservation, $143,42-51$.

Wolf, C. \& Ripple, W.J. (2017) Range contractions of the world's large carnivores. Royal Society Open Science, 4, 170052. 